\title{
HISTORIAS DE TABERNA GALÁCTICA, DE JOSEP MARÍA BEÀ. CIENCIA FICCIÓN CON UNA HUELLA PERSONAL
}

\author{
Julio A. Gracia Lana \\ Universidad de Zaragoza
}

\section{RESUMEN}

Josep María Beà (Barcelona, 1942) es uno de los historietistas más relevantes de la historia reciente del cómic en Espańa. El artículo se plantea como una primera aproximación a su producción y específicamente se centra en una de sus obras más representativas, Historias de Taberna Galáctica (publicada en la revista 1984). El análisis se centra tanto en los aspectos narrativos como en la iconografía, destacando la importancia de la obra en el contexto del boom del cómic adulto.

Palabras clave: cómic adulto, Josep María Beà, ciencia ficción, Historias de Taberna Galáctica, 1984.

\section{JOSEP MARÍA BEÀ'S HISTORIAS DE TABERNA GALÁCTICA. SCI FI WORKS WITH A SPECIAL TOUCH}

\section{Abstract}

Josep María Beà (Barcelona, 1942) is one of the most relevant cartoonists in the recent history of comics in Spain. The article is presented as a first approximation to his production and is specifically focused on one of his most representative works, Historias de Taberna Galáctica (published in the magazine 1984). This analysis focuses on the narrative aspects as well as iconography, highlighting the importance of the work in the context of the adult comic boom.

Keywords: adult comics, Josep María Beà, science fiction, Historias de Taberna Galáctica, 1984. 


\section{JOSEP MARÍA BEÀ Y EL BOOM DEL CÓMIC ADULTO}

Josep María Beà (Barcelona, 1942) es una de las firmas más importantes de la historia del cómic en España. Desde su niñez y al igual que otros compañeros de generación, estuvo muy vinculado al medio. De forma hiperbólica destaca que «amaba tanto los tebeos, que a los ocho añitos de edad, lamía las portadas de los mismos hasta dejar el papel en blanco, me encantaban el sabor y el aroma de la tinta de imprenta de los cuadernos recién impresos» ${ }^{1}$. Flash Gordon o El hombre enmascarado fueron algunas de sus primeras lecturas internacionales, mientras que $\mathrm{Haza}$ ñas Bélicas y las aventuras de El Inspector Dan, que se publicaban en Pulgarcito, se encontraban entre lo que más le gustaba del material editado desde España. Estas influencias iniciales fueron las raíces sobre las que creció su producción, amplia y diversa. El texto se configura como una primera aproximación a la misma y específicamente se centra en una de sus historias más características y reconocidas, enmarcada en el territorio de la ciencia ficción: Historias de Taberna Galáctica.

Los primeros influjos que hemos citado fueron decisivos para el desarrollo de la obra de Beà. El autor llegó incluso a conocer al creador de Hazañas Bélicas, Boixcar (Guillermo Sánchez Boix),

que en aquellos tiempos alpargateros era más conocido que Caniff, Foster y Raymond juntos. El hombre me recibió en su casa y me invitó a sentarme a su lado para que pudiera observar cómo realizaba una página. Se ausentó un momento de la mesa de dibujo, salió de la habitación. Entonces, un intrépido servidor, cogió la pluma del dibujante y marcó con ella un PUNTO al pie de una viñeta. Veinte días después, fui al quiosco y compré el Hazañas Bélicas y jallí estaba mi PUNTO! ¡Mi primer trabajo profesional distribuido a lo largo y ancho de la península! Lo mostré orgulloso a familiares y amigos. Hasta lo miré a través de una lupa: ¡Vaya PUNTO! Años después se lo conté a Boixcar. La vida es un cómic, me dijoº .

Más allá de las anécdotas desgranadas por el historietista, lo que queda claro es que sus primeras lecturas fueron principalmente en clave de género y le inspiraron para convertirse en historietista. Desde muy joven entró a formar parte de la agencia Selecciones Ilustradas, comandada por Josep Toutain, «un sujeto muy especial. Practicaba un comportamiento ora autoritario, ora paternalista» ${ }^{3}$. Contó con el apoyo de Rafael López Espí, cinco años mayor que Beà, y dibujó durante varios años cientos de originales. La empresa «funcionaba como una fábrica, cada día tenían que salir de ella docenas de páginas para ser enviadas al mercado exte-

${ }^{1}$ Barrero, Manuel (2003): «Cosiendo olas con tonsura descentrada. Entrevista a J.M. Beà», Tebeosfera, Sevilla, https://www.tebeosfera.com/1/Documento/Entrevista/Bea/JM.htm (fecha de consulta: 27-VII-2019).

2 Ibidem.

3 El Tío Berni (10-VI-2008): «Entrevista a Josep María Beà», Entrecomics, http://www. entrecomics.com/?p=15963 (fecha de consulta: 27-VII-2019). 
rior (...). Cualquier muchacho con un poco de mano para el dibujo llegaba a SI, lo sentaban en una mesa y en quince días ya estaba trabajando» ${ }^{4}$.

El sistema permitía ganar mucho dinero a los dibujantes, «si el sueldo medio interprofesional era de, digamos, diez, nosotros estábamos en cien. Era una barbaridad ${ }^{5}$. Además, el trabajo para la agencia le permitió acumular experiencia rápidamente. Sin embargo, también le produjo un cierto sentimiento de desencanto ante una producción sobre la que apenas tenía control creativo. Este hecho explica en parte que en 1962 Beà lo dejara todo y acudiera a estudiar pintura a la prestigiosa Académie Julian de París. Vivió varios años en la capital francesa, pero se dio cuenta

de que persistía todavía la ilusión del cómic, de narrar. Coincidió en 1968 con el inicio de un movimiento en toda Europa [...] que buscaba la intelectualización del cómic y que se empezase a considerar como un vehículo de transmisión de ideas tan válido como podían ser la literatura, el cine o la pintura. Me llamaron en ese momento Enric Sió y Esteban Maroto y me dijeron que en Barcelona iba a pasar también algo [...]. Luis Gasca comenzó a editar la revista Drácula, que nos permitió hacer lo que quisiéramos. Lo que ahora puede parecer una tontería, en aquel momento fue un riesgo, una propuesta muy arriesgada ${ }^{6}$.

En la joven revista, el autor gozó por lo tanto de una amplia libertad, en contraste con la producción en masa que había realizado de manera mayoritaria para Toutain. Recibía asimismo una suma económica importante por las páginas que realizaba para la publicación. Valoración editorial y apoyo económico constituyeron un dúo perfecto que nos permite hablar de un "punto de inflexión trascendental» en su trayectoria. Un avance hacia su condición de autor, tal y como él mismo destaca ${ }^{7}$. Continúa tratando el género, en este caso el terror sobre guiones de Luis Vigil, Esteban Maroto o de él mismo, pero con un control absoluto sobre su dibujo, que le lleva a aplicar nuevas técnicas, entre ellas el frottage.

Los encargos para la editorial norteamericana Warren Publishing terminaron de completar parte del tiempo empleado por Beà en la historieta durante los setenta. Sus cómics gozaron de éxito en Estados Unidos y le granjearon las felicitaciones de reputados autores del momento. En sus historias de esa época «se puede descubrir en mi trabajo reminiscencias prerrafaelistas, surrealistas, dadaístas, esquemas de viejos grabadores como William Hogarth, Heinrich Kley, Mervyn Peake, Max Klinger, Fred Walker, o la faceta fotográfica del pintor Ben Shahn» ${ }^{8}$. Su entrada en el conocido como boom del cómic adulto se produjo, por lo tanto, con mucha experiencia acumulada, pero siendo todavía joven, y con una conciencia autoral cada vez más marcada.

\footnotetext{
4 Barrero, Manuel (2003): "Cosiendo olas con tonsura descentrada...", op. cit.

5 Entrevista a Josep María Beà en Barcelona, realizada el 24-IV-2017.

6 Ibidem.

7 Barrero, Manuel (2003): "Cosiendo olas con tonsura descentrada...», op. cit.

8 Ibidem.
} 
Al hablar del boom nos referimos al auge de publicaciones que se dio entre la segunda mitad de los años setenta y mediados de la década siguiente en nuestro país, coincidiendo con la Transición y los primeros años de la democracia. La teórica Francesca Lladó analiza la revista como el formato más característico de este fenómeno 9 . A nivel editorial destacaron de manera inicial dos empresarios: Roberto Rocca y, especialmente, Josep Toutain. El primero hizo que desembarcara en España la editorial Nueva Frontera, con la publicación prácticamente al mismo tiempo y de manera precursora de las revistas Totem, Blue Jeans (ambas editadas en 1977) y Bumerang (1978). Por otra parte Toutain, a través de Toutain Editor (reconversión de la agencia Selecciones Ilustradas), fue el responsable de publicaciones entre las que se encontraban Creepy (1979) o 1984 (1978), en la que apareció Historias de Taberna Galáctica. Para Pepo Pérez «el modelo de Toutain había surgido [...] con las publicaciones de Ibero Mundial de Ediciones y Garbo Editorial, por un lado, y la revista Totem, por otro ${ }^{10}$.

Muchos editores se sumaron a la oportunidad ofrecida por el contexto. Un antiguo empleado de Toutain, Rafael Martínez, fue el responsable primero de la agencia y más tarde de la editorial Norma, encargada de revistas tan simbólicas del fenómeno como Cimoc (1981). También fue Toutain el que posibilitó el surgimiento de Ediciones La Cúpula y, con ella, de la revista El Víbora (1979), al prestar dinero a Josep María Berenguer para que hiciera posible la publicación. Tal y como destaca Antonio Altarriba, «entre 1981 y 1985, los años de mayor proliferación de títulos, llegaron a coincidir en los quioscos y, como consecuencia a competir, cerca de veinte publicaciones ${ }^{11}$. En este contexto favorable a los autores, Beà realizó sus historietas más personales. En sus propias palabras:

Es justo que se me asocie al boom. Además es cuando más producción tengo. Hay que pensar que en un periodo de unos siete años realizo Historias de la Taberna Galáctica, En un lugar de la mente, La muralla, Siete vidas o La esfera cúbica y luego hago varias historias para Makoki. De forma que en los años ochenta se concentran todas las historias más adultas y sinceras, en las que cuento lo que más me interesa. Teniendo todavía treinta y ocho o treinta y nueve años, siendo joven aún ${ }^{12}$.

9 Francisca Lladó centra el libro trasunto de su tesis doctoral en el análisis de las revistas producidas en esta etapa. Significativamente, el primero de los tres capítulos en los que se divide el mismo se dedica a «Evolución y estructura interna de las revistas de cómic». Lladó, Francisca (2001): Los Cómics de la Transición (El boom del cómic adulto 1975-1984), Barcelona, Glénat.

${ }^{10}$ Pérez, Pepo (2018): «¿ «Solo para adultos»? Del boom al crack. La ficción de género en las revistas españolas de cómic de los ochenta», en Vilches, Gerardo (coord.): Del boom al crack. La explosión del cómic adulto en España (1977-1995), Madrid, Diminuta Editorial, 2018, pp. 57-92, espec. p. 58.

${ }_{11}$ Altarriba, Antonio (2001): La España del Tebeo. La Historieta Española de 1940 a 2000, Madrid, Espasa Calpe, p. 320.

12 Entrevista a Josep María Beà en Barcelona, realizada el 24-IV-2017. 


\section{LA NARRACIÓN EN HISTORIAS DE TABERNA GALÁCTICA}

Entre todas estas obras, como destaca Iván Olmedo, Historias de Taberna Galáctica «es la obra más conocida y reconocida del barcelonés Josep Maria Beà i Font, así como uno de los títulos mejor recordados y mitificados de nuestra reciente historia de los cómics en España» ${ }^{13}$. Desde el punto de vista de su trayectoria, la creación de Historias llegó, por una parte, en un momento de consolidación de Beà en el panorama del boom del cómic adulto. El autor definió con Toutain

el siguiente pacto: cuando yo entregaba una historia, él me anticipaba los derechos de autor de la edición española, que sería 1984. Pero luego también me anticipaba los derechos de la edición en Estados Unidos, que era Heavy Metal, y de la italiana o de la francesa. Es verdad que eran cantidades pequeñas, pero claro, si de golpe te anticipan el diez por ciento de la venta de los derechos en esos países, te vas a casa con un buen sueldo ${ }^{14}$.

Por otro lado, a nivel personal y una vez más siguiendo las propias palabras de Beà:

Taberna es el resultado de un estado de la mente alterado artificialmente, donde mi interés reside más en la obtención de un imaginario surreal (representaciones conscientes de un desplazamiento con respecto al sentido inconsciente) que una argumentación de base lógica (aunque finalmente, procuro que todos los capítulos estén sujetos a la tradicional fórmula del planteamiento, nudo y desenlace. No puedo permitirme la frivolidad de que el lector, por mi deseo de jugar con la psique, caiga en un marasmo de relatos ininteligibles) ${ }^{15}$.

Las historias se prolongaron desde el número once de la revista 1984 hasta el veintiocho. La publicación había surgido claramente dirigida a nivel editorial a la edición de relatos de ciencia ficción. Su nombre, 1984, hacía referencia al título de la distopía futurista escrita por George Orwell [fig. 1]. En su editorial inicial se declaraba que:

sólo cincuenta años atrás, algunas de las realidades que hoy gozamos o sufrimos, eran consideradas fantasías irrealizables, producto de mentes calenturientas.

(...) El hombre paseándose por la Luna... (...)

13 Olmedo, Ivan (2003): «Historias de Taberna Galáctica», Tebeosfera, Sevilla, https:// www.tebeosfera.com/1/Obra/Tebeo/Glenat/TabernaGalactica.htm (fecha de consulta: 27-VII-2019).

${ }^{14}$ Entrevista a Josep María Beà en Barcelona, realizada el 24-IV-2017.

${ }^{15}$ Mora, Javier y Barrero, Manuel (2009): «Beà. Psiconauta de la historieta», Tebeosfera 3, 2009, Sevilla, https://www.tebeosfera.com/documentos/bea._psiconauta_de_la_historieta. html (fecha de consulta: 27-VII-2019). 


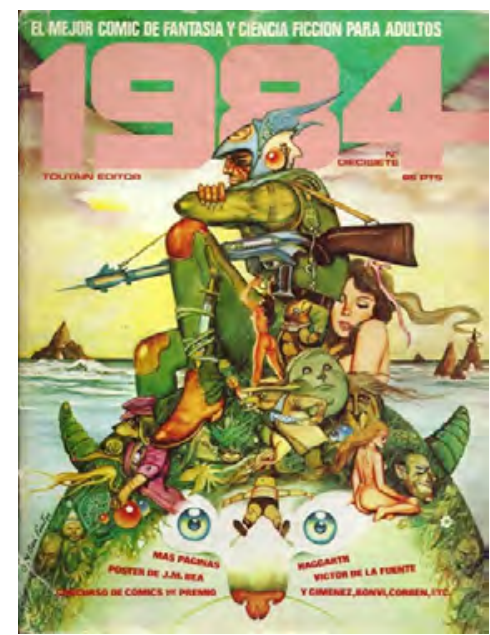

Fig. 1. Portada de Beà para el número 17 de 1984, Barcelona, Toutain Editor, 1980.

Visionarios del pasado, muchos de ellos tachados de locos, se valieron de la literatura y otros medios de su época para anticipar un futuro que ha resultado cierto en la mayoría de los casos.

\section{(...)}

Nosotros, profesionales del cómic, amantes de todo lo que signifique creatividad, imaginación y fantasía, pretendemos acompañar a nuestros colegas novelistas, cineastas e investigadores a través de $1984^{16}$.

Continuaba así la senda de la revista homónima norteamericana que había comenzado a editar Warren Publishing. La publicación incluía mucho material de origen americano, con autores como Richard Corben o Wally Wood. Se dieron cita también españoles como Luis Bermejo o Esteban Maroto, este último con series como La esfinge.

La primera de las historias concebidas por Beà, «Unidad de servicio $3 \mathrm{M}$ », presenta a la «Taberna Galáctica» como un «bar de una estación de recreo en el espacio, constelación M». Una serie de extraños personajes se encuentran alrededor de una mesa bebiendo y dispuestos a escuchar el relato de uno de ellos, que se desarrolla en las vińetas siguientes. El grupo lo configuran, entre otros, un reptil en el que leemos elementos antropomorfos, ataviado con unos pantalones bombachos a rayas, una mujer con rasgos reptilianos, una suerte de iguana de gran tamaño, erguida, que degusta una bebida caliente, o un cánido con sombrero, gafas y un ins-

16 Editor (1978): «Presentación», 1984, 1, Barcelona, Toutain Editor, p. 2. 
trumento mecánico en el oído. Todos ellos escuchan a un ser antropomorfo, apodado "el tío Nemo", que porta unas gafas extravagantes y cuyas manos han sido sustituidas por garfios.

El cuento que se dispone a narrar «ocurrió en un pobre planeta de la Galaxia C. Terminó tan mal y tan pronto la vida humana en dicho pedrusco que mejor no hubieran tenido sus habitantes, dios que los creara $»^{17}$. Es una alusión al propio planeta Tierra y a un momento de tecnificación similar al actual, en el que los robots pueden recibir y ejecutar órdenes sencillas, al tiempo que avanza su introducción dentro del ámbito doméstico. El dueño de una casa queda atrapado cuando intenta mover una carga muy pesada y su robot, programado un momento antes con el piloto automático, no alcanza a comprender lo que su dueño necesita, ocasionando la muerte de éste. Cuando el relato finaliza, recibe una fuerte crítica de todos sus oyentes, que quitan trascendencia a las reflexiones que se desprenden de lo contado. «Barato melodrama», en palabras del reptil de originales pantalones.

Este primer cuento establece así el esquema de todos los demás: un inicio y un final en el ambiente de la Taberna Galáctica ${ }^{18}$ y un nódulo central constituido por la historia de uno de los contertulios. Se pasa de la trascendencia a la ironía y se explora una amplia variedad temática de propuestas vinculadas a la ciencia ficción. Se proponen así distintos relatos con un hilo común propiciado por el lugar desde el que se emiten.

En verdad, esta estructura entronca con una de las concepciones más antiguas y paradigmáticas de la narrativa, ya que

el cuento, en sus orígenes históricos, fue una diversión dentro de una conversación; y la diversión consistía en sorprender al oyente con un repentino excursus en el curso normal de la vida [...]. Los jeroglíficos sobre rollos de papiro, en Egipto, solían describir una situación en la que varios personajes, al conversar, contaban cuentos [...]. En Homero (siglo IX a.C.), además de las aventuras que surgen directamente de la acción hay escenas en que los personajes, alejados de esa acción, se ponen a conversar. Así, conversando en el palacio de Alcinoo, cuenta Odiseo sus aventuras con los Cíclopes, con Circe, con las Sirenas, con Calipso ${ }^{19}$.

"Es como Los cuentos de Canterbury o Las mil y una noches. Gente que se reúne para contar una historia [...]. La reunión de unas personas contando una historia es muy antiguo $»^{20}$. Este esquema narrativo permitía al autor trabajar varios

17 BEÀ, Josep María (1979): «Unidad de servicio 3M», 1984, 11, Barcelona, Toutain Editor, pp. 50-57, espec. p. 50.

${ }^{18}$ Sólo hay una excepción: el «relato de Romagosa» tiene lugar en un hospital o consultorio espacial.

19 Anderson Imbert, Enrique (1992): Teoría y técnica del cuento, Barcelona, Editorial Ariel, pp. 23-24.

${ }^{20}$ Infame\&Co (31-VIII-2017): “Mi vida siempre ha sido algo surrealista”. Entrevista a Josep María Beà", El Portaluco, https://elportaluco.com/vida-siempre-ha-algo-surrealista-entrevista-josep-maria-bea/ (fecha de consulta: 27-VII-2019). 
temas y propiciaba la atención del lector en cada número de la revista. Siguiendo esta línea, Anderson Imbert nos refiere la forma en la que funciona el esquema del cuento en el lector al compararlo con

el móvil psicológico que lleva a un hombre o a una mujer a intervenir en una conversación para contar algo. Esa persona está viviendo normalmente, en un presente abierto al provenir. De súbito un incentivo cualquiera le despierta un recuerdo o las ganas de inventar una aventura. Su vida, abierta al porvenir, ha entrado en momentánea clausura: ahora esa persona se prepara para referirnos un lance, real o imaginario, que transcurrió en un tiempo pretérito [...]. Al contar su cuento el cuentista asume la postura psicológica de un conversador que sabe que la atención de su público dura poco y por tanto debe redondear rápidamente ciertos acontecimientos y producir un efecto antes de que lo interrumpan o lo desatiendan. Tiene que ser breve [...]. Lo que urge al cuentista es impresionar a los lectores más con una acción que con los agentes de la acción; con la singularidad de una aventura más que con el carácter del aventurero. Se ajusta a la trama de la acción. El lector de un cuento literario, igual que el oyente de un cuento oral, no quiere descripciones ni comentarios sobre lo que siente y piensa el protagonista. Quiere enterarse de lo sucedido, y de una sola vez ${ }^{21}$.

\section{TEMAS E ICONOGRAFÍA}

El esquema narrativo se enmarca dentro del género de la ciencia ficción. Entendemos los géneros como «modelos dinámicos y abiertos»" $»^{22}$ con una historia larga y compleja, de manera que "ya podríamos observar los primeros intentos de ciencia ficción durante el siglo XIX $»^{23}$. Fernando Ángel Moreno aporta rasgos amplios al género literario, que podemos trasladar al cine o al cómic, entendiendo que la ciencia ficción

debe incluir elementos que no existen en nuestro mundo empírico. Al fin y al cabo, nos encontramos ante una forma de fantasía, aplicando el término en su sentido más general; de proyección, mejor. Sin embargo, no puede incluir elementos sobrenaturales, es decir-siguiendo la definición de «sobrenatural» del DRAE-, no debe exceder los términos de la naturaleza. No es tan importante que el aval científico sea verificable en el mundo «real», como la pretensión del autor y la consiguiente aceptación del lector de que los hechos presentados no conlleven una visión sobre-

${ }^{21}$ Anderson Imbert, Enrique: op. cit., pp. 24-25.

22 Martín Cerezo, Iván (2006): «Poética del relato policiaco (de Edgar Allan Poe a Raymond Chandler)», Murcia, Universidad de Murcia, Servicio de Publicaciones, p. 18.

23 Ángel Moreno, Fernando (2007): «Notas para una historia de la ciencia ficción en España», Dicenda: Estudios de lengua y literatura españolas, 25, Madrid, Universidad Complutense, Servicio de Publicaciones, pp. 125-138, espec. p. 126. 


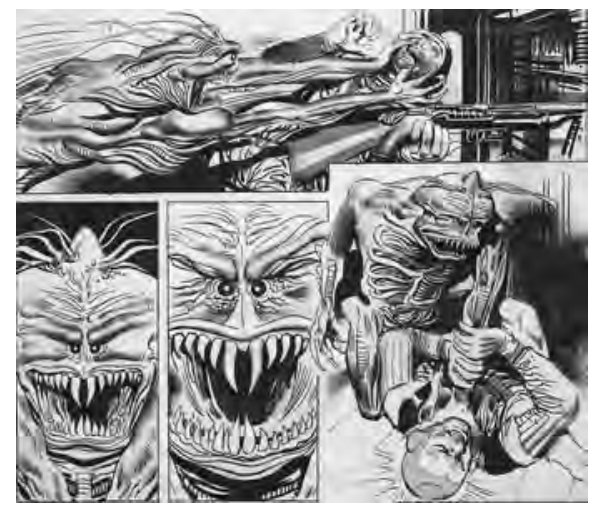

Fig. 2. Viñetas que muestran el combate entre los dos protagonistas de "Relato de Khantrax», en el número 17 de 1984, Barcelona, Toutain Editor, 1980, pp. 55-62, espec. p. 58.

natural, extra-científica, de la realidad. Esto es, se busca una relación directa con la realidad, no una evasión de la misma ${ }^{24}$.

Dentro de esta idea del género, algunas historias muestran las concepciones personales y la libertad del propio autor. Entre ellas se encuentra «Relato de Romagosa", que presenta los conflictos entre un chico superdotado que quiere elegir su propio destino y un padre castrante que busca imponérselo. En «Relato de Hycrotan» se produce un encuentro entre un hombre y una misteriosa señal, que le lleva a un estado de percepción superior y hace que se termine fusionando con el cosmos. Todo ello tras haber hilvanado mentalmente una serie de tragedias de la humanidad que parecían no tener conexión entre sí.

Los desencuentros entre humanos y otras formas de vida, robóticas o extraterrestres, dan lugar a distintas historias. "Relato de Toksath» plantea la llegada de un extraño ser de un solo ojo a la celebración que se está produciendo en una mansión de época victoriana. «Relato de Ondrakor» muestra la muerte del último hombre en un planeta totalmente ocupado por los androides. En directo, ante miles de ellos, se pronuncian en alto los últimos segundos durante los que el ser humano mantiene sus constantes vitales. En «Relato de Tenyktar», la adicción al juego provoca que un asesino se convierta paulatinamente en robot para conseguir más dinero que apostar. Pierde los brazos, las piernas, el cuerpo y, finalmente, su propia cabeza.

«Relato de Khantrax» versa sobre la convivencia violenta entre un humano y un alienígena en una nave cerrada [fig. 2], con un giro final que invierte los roles de ambos que había presupuesto inicialmente el lector. También resulta violenta la

24 Ángel Moreno, Fernando (2010): Teoría de la Literatura de Ciencia Ficción. Poética y Retórica de lo Prospectivo, Vitoria, Portal Editions, p. 105. 
relación entre la humanidad y una suerte de simbionte con apariencia de barro que se da en "Relato de Kiramow». Y, una vez más, entre las personas y unos extraños seres en "Relato de Syanock». Los habitantes de otro planeta consiguen un crecimiento desmesurado y repentino de la vegetación, invadiendo a los propios cuerpos de los pobladores del globo. Al final de este relato, el narrador dialoga con otro personaje, rompiendo parcialmente la cuarta pared:

- ¿Pero por qué motivo en estos relatos otorgáis siempre a los invasores características de entes devastadores, malignos y destructivos? (...).

- Te equivocas en lo de destructivo. Se produjo una repoblación forestal en pocos días, y ahora aquél es el planeta más verde de su sistema... Falta le hacía... ${ }^{25}$.

Sin embargo, en «Relato de Blydhan» se desarrolla un encuentro mucho más amable entre un joven humano y un extraterrestre. Este último posee muchos prejuicios morales en comparación con los del resto de su raza. Los alienígenas entendidos como parte de un universo fantástico que el humano protagonista no termina de definir se dan cita en "Relato de Nacrapt». El habitante de otros mundos aparece amenazante, pero el terráqueo no se da cuenta en ningún momento. Todo un toque, una vez más, irónico, en el lápiz de Beà.

Algunas historias se desarrollan en la inmensidad del espacio o en la desolación de un planeta y juegan con un cierto melodrama. Es el caso de «Relato de Okaris», cuya trama gira en torno a un accidente en una nave espacial, que deja a dos de sus tripulantes perdidos en la oscuridad. "Relato de Wanshott» habla de mutaciones y pequeños universos en otros gigantescos, con el marco de un entorno contaminado y opresivo.

El sexo es un tema transversal, presente no tanto en los relatos como en la propia taberna galáctica, actuando así, por lo tanto, como marco de las historias. Los personajes aparecen totalmente obsesionados por el tema. Beà idea productos y nuevas técnicas espaciales, como el "psicofén», el «ultrasex», o el "pornolograma»" En «Relato de Khantrax» el diálogo entre el narrador y un personaje de aspecto cercano a un pequeño pájaro resulta muy explícito:

- Pero jes que en esta sala no pensáis en otra cosa que no esté relacionada con el sexo?

- Pues mira, Khantrax, bonito, resulta que en esta sala solo pensamos en eso ${ }^{27}$.

${ }^{25}$ BEÀ, Josep María (1980): «Relato de Syanock», 1984, 26, Barcelona, Toutain Editor, pp. 64-71, espec., p. 71.

26 BEÀ, Josep María (1980): «Relato de Tenyktar», 1984, 18, Barcelona, Toutain Editor, pp. 57-64, espec. p. 57.

27 BEÀ, Josep María (1980): «Relato de Khantrax», 1984, 17, Barcelona, Toutain Editor, pp. 55-62, espec. p. 55 . 
En «Relato de Okaris», el cuentista reprocha al resto de personajes que se hayan abandonado «a irrefrenables vorágines orgiásticas» ${ }^{28}$, mientras que en «Relato de Zherbis» dos personajes contemplan a un hombre desnudo y se preguntan qué es el extrańo apéndice "que le pende entre las piernas»" ${ }^{29}$.

Muchos de estos relatos retoman temáticas extraídas de la ciencia ficción más paradigmática. Con ironía, dos personajes relatan el final de "Relato de Ondrakor». Cuando el último hombre del planeta muere y deja tras de sí un universo metálico, el narrador destaca que «fue tan progresivo el avance científico en el planeta, que al cabo de unos ańos los robots se propusieron llevar a término un ambicioso objetivo: crear la vida. Han vuelto a crear al hombre... pero ahora lo tienen a su servicio». A ello, una suerte de gato antropomorfo de poblado bigote y una mujer humana responden:

- Típica venganza cibernética... o el colmo de la nostalgia.

- Si es lo que digo siempre: que ya está todo descubierto... ${ }^{30}$.

Del mismo modo, en «Relato de Khantrax», uno de los personajes declara mordazmente sobre la historia narrada: «El comandante de una nave tiene que deshacerse de un alienígena ¿Esto es una insólita historia?’”31.

El autor no buscó con estos relatos presentar una moraleja, a modo de fábula clásica, al lector, sino delimitar los límites del género humano con una profunda dosis de humor negro. Beà lo resume estableciendo que buscaba narrar «la pesadilla de la existencia [...]. La gente es muy desgraciada y nadie sale vencedor. Este era un poco el espíritu de la taberna: reflejar un poco la pesadilla de la humanidad ${ }^{32}$. El último de los cuentos, «Relato de Clakster», incluye a nivel narrativo palabras inventadas por el historietista, como «brogas» o "parcoraderas». Desde el punto de vista gráfico, Beà deja volar su imaginación con una serie de formas inestables, «blandas», que recuerdan al surrealismo y parecen aproximarse al Salvador Dalí de El Gran Masturbador (1929). El autor finaliza las historias de la taberna cerrando sus puertas una vez que «este negocio ha dejado de ser rentable» y confesando como narrador absoluto de todas las historias: «No haber comprendido en absoluto el relato expuesto por Clakster. Asimismo considero que sería, por mi parte, un acto de suprema soberbia negar su veracidad $\aleph^{33}$.

${ }^{28}$ BeÀ, Josep María (1980): «Relato de Okaris», 1984, 19, Barcelona, Toutain Editor, pp. 57-64, espec. p. 64.

${ }^{29}$ BEÀ, Josep María (1980): «Relato de Zherbis», 1984, 22, Barcelona, Toutain Editor, pp. $53-60$.

30 BEÀ, Josep María (1980): «Relato de Ondrakor», 1984, 16, Barcelona, Toutain Editor, pp. 6-9, espec. p. 9.

31 BeÀ, Josep María (1980): «Relato de Khantrax», op. cit., p. 62.

32 Infame\&Co: op. cit.

33 BEÀ, Josep María (1981): «Relato de Clakster», 1984, 28, Barcelona, Toutain Editor, pp. 69-72, espec. p. 72. 
El dibujo empleado en la práctica totalidad de las narraciones resulta de un preciso realismo, que entronca con las lecturas juveniles de Beà y con autores de origen norteamericano, como Alex Raymond o Burne Hogarth ${ }^{34}$. Francisca Lladó destaca además, entre otros rasgos estéticos, «las fuertes gradaciones de luz conseguidas a través de la utilización de plumilla» ${ }^{35}$.

Realismo en el trazo que se plasma en las viñetas con una desbordante imaginación. Desde el prisma iconográfico, la taberna galáctica donde se desarrollan los relatos nos remite a un antecedente muy claro: la Cantina de Chalmun o de Mos Eisley, introducida en el film Star Wars: Episode IV-A New Hope (1977), dirigido por George Lucas. Mal iluminada, entretenida y llena de todo tipo de personajes extraídos de los más recónditos lugares de la galaxia, con el wookiee Chewbacca y el cazarrecompensas Han Solo entre ellos. Visualmente, el autor se recrea en la configuración de los personajes o en algunos detalles aparentemente fútiles en el relato, como los naipes de "Relato de Tenyktar». Son oníricos e inquietantes a partes iguales, con títulos absolutamente descriptivos, como «La mujer que mata la mano del caracol» $\mathrm{o}$ «La muerte a los cuatro años tocando el tambor con dos espermatozoides». Un gato similar a los que más adelante formaron parte de la obra Siete Vidas, firmada también por el historietista, se desliza al principio de "Relato de Ondrakor ${ }^{36}$ o sirve como narrador en «Relato de Okaris» ${ }^{37}$.

Beà introduce además referentes extraídos de la historia del arte. En «Relato de Toksath» incluye una cita a La última cena pintada por Leonardo da Vinci en el siglo XV, en la que Jesús y los Apóstoles son sustituidos por alienígenas ${ }^{38}$. Las referencias del historietista son muy amplias y abarcan desde citas de famosos lienzos hasta personajes extraídos del mundo del cómic, como el propio Conan el Bárbaro, que aparece en la última vińeta de "Relato de Tenyktar" ". La combinación de alusiones variadas que abarca desde al arte hasta el pop podía quizás aumentar el impacto y la consideración global de la obra, entendida como un producto cultural capaz de cruzar fronteras y de venderse en distintos mercados. Al fin y al cabo, como destaca Pedro Pérez del Solar, en revistas de Nueva Frontera y de Toutain se publicaban las historietas españolas "que habían demostrado su viabilidad comercial en revistas extranjeras. Las nuevas obras de autores locales que trabajaban para el extranjero fueron entrando poco a poco» ${ }^{40}$.

34 García Rouco, Diego y Cardona, Tristán (01-V-2019): «Entrevista a Josep M. ${ }^{a}$ Beà», Zona Negativa, https://www.zonanegativa.com/entrevista-a-josep-ma-bea/ (fecha de consulta: 27-VII2019).

35 Lladó, Francisca: op. cit., p. 64.

${ }^{36}$ BEÀ, Josep María (1980): «Relato de Ondrakor», op. cit., p. 6.

37 BEÀ, Josep María (1980): «Relato de Okaris», op. cit.

38 BEÀ, Josep María (1979): «Relato de Toksath», 1984, 14, Barcelona, Toutain Editor, pp. 49-56, espec. p. 49.

39 BEÀ, Josep María (1980): «Relato de Tenyktar», 1984, 18, Barcelona, Toutain Editor, pp. 57-64, espec. p. 64.

40 Pérez del Solar, Pedro (2013): Imágenes del desencanto. Nueva historieta española 19801986, Madrid y Fráncfort, Iberoamericana / Vervuert, p. 28. 


\section{REFLEXIONES FINALES}

De esta forma, la obra mantiene una gran importancia dentro de la producción de Beà y en el contexto del boom del cómic adulto. Poco después del éxito de Historias de Taberna Galáctica, el dibujante se embarcó en la realización de En un lugar de la mente. Concebida también para la revista 1984, resulta razonable

que pudiéramos encontrar ciertas confluencias entre una y otra dado el escaso margen de tiempo entre ambos trabajos. Y así ocurre: una colección de cuentos enlazados a través de un tema común, una imaginería ambientada en torno a la ciencia ficción... Demasiado fácil. Si realizamos un análisis atento de estas dos pesquisas podremos observar como en un principio la realidad profunda que las sustenta es otra bien distinta. Tan distinta que ambos rasgos en sus orígenes lejos de mostrar las semejanzas entre las obras ya citadas, se encargaban más bien de sustentar y afianzar una voluntad de distanciamiento pleno y consciente ${ }^{41}$.

El boom permitió que el historietista fuera más allá y llevara a cabo además historias como La esfera cúbica, La Muralla o Siete Vidas. Para publicar muchas de sus propuestas, Beà contó con una plataforma nueva: la revista Rambla; publicación autogestionada comandada por él mismo y por el también dibujante Luis García durante todo su recorrido, contando en diferentes momentos con el apoyo de autores como Carlos Giménez o Marika Vila.

Sin embargo, el auge de la historieta adulta vehiculada a través de las revistas fue progresivamente decayendo. Del boom pasó a la caída. Rambla cerró por falta de viabilidad. Cairo o Cimoc (editadas por Norma Editorial) dejaron de ocupar los quioscos. 1984, la revista que había acogido Historias de Taberna Galáctica, se transformó tras el número sesenta y cuatro en Zona 84, no sin plantear antes «un referéndum popular» con «muchísimos más títulos que votantes» ${ }^{42}$. Esta última publicación dejó a su vez de editarse tras noventa y seis números, constituyéndose como un ejemplo más de que «la circunstancia histórica que favoreció la realización de tantos grandes cómics que esta y otras revistas volcaron sobre el hambriento aficionado español, es irrepetible» ${ }^{43}$. Las causas de esta desaparición fueron variadas: desde el auge de nuevos medios como el videojuego hasta el aumento de los precios del papel. Como resume Álvaro Pons «cualquiera de las causas tiene potencial para ser origen de la crisis ${ }^{44}$.

${ }^{41}$ Mora Bordel, Javier (2003): «En un lugar de la mente», Tebeosfera, Sevilla, https:// www.tebeosfera.com/1/Obra/Tebeo/Glenat/EnunLugarde...2.htm (fecha de consulta: 27-VII-2019).

${ }^{42}$ Anónimo (1984): «Anecdotario», 1984, 64, Barcelona, Toutain Editor, pp. 4-5, espec., p. 4.

43 Toutain, Josep (1992): «Comix \& Comics», Zona 84, 96, p. 4.

44 Pons, Álvaro (2011): «La industria del cómic en España: Radiografía de ¿̨un mito o una realidad?», ARBOR Ciencia, Pensamiento y Cultura, 187, EXTRA 2, pp. 265-273, espec. p. 268, http://arbor.revistas.csic.es/index.php/arbor/article/view/1381/1390 (fecha de consulta: 27-VII-2019). 
Con la progresiva caída de las publicaciones periódicas, muchos autores pasaron a trabajar para otros medios entre la segunda mitad de los años ochenta y la década siguiente. En el caso de Beà, se interesó

por la soldadura, por el montaje de estructuras mecánicas con residuos. Hubo también un proyecto para la versión televisiva de Historias de Taberna Galáctica y allí trabajé mucho construyendo maquetas y animatronics. La escultura con acetileno era también apasionante...

En el fondo también estaba narrando, me encontraba construyendo con acetileno pero surgía un mensaje. Miraba aquello y pensaba: en el fondo es lo mismo, no sale algo amable, no aparece el Pato Donald [risas]. Hay algo allí que es materia de análisis psicológico...

Tanto en uno como en otro medio, siempre he transmitido un mensaje de decepción ante todo, de descreencia ${ }^{45}$.

Al margen de su relativa brevedad, el boom nos permitió disfrutar de una interesante etapa de creación, de la que sirve como ejemplo sintomático Historias de Taberna Galáctica. La obra presenta una narrativa que bebe del cuento clásico, con una estructura que puede recordar a producciones como Los cuentos de Canterbury. Los diferentes relatos introducidos se mueven en el territorio de la ciencia ficción, con dobles historias (las de la propia taberna y las narradas por sus clientes) de gran diversidad que cuentan con leitmotivs recurrentes, como la presencia del sexo. En todas ellas, el autor buscó explorar y transmitir su visión sobre la naturaleza humana. Lo hizo a través de un trazo realista que plasmaba una iconografía muy original. No resulta extraño por lo tanto que el cómic fuera recopilado por Toutain ${ }^{46} \mathrm{y}$ reeditado por Glénat ${ }^{47}$ o por Trilita Ediciones ${ }^{48}$. El objetivo del autor de mostrar a través de estos relatos al ser humano de forma explícita, encaja con la idea de que la ciencia ficción es un género alejado sólo «aparentemente de los hechos reales» ${ }^{49}$ y que «pretende que el lector jamás olvide que todo lo desarrollado tiene que ver con la parte más cruda y profunda de la realidad $\aleph^{50}$.

Las mejores conclusiones vienen proporcionadas, una vez más, por las propias palabras de Josep María Beà:

Trilita Ediciones.

45 Entrevista a Josep María Beà en Barcelona, realizada el 24 de abril de 2017.

46 BEÀ, Josep María (1981): Historias de Taberna Galáctica, Barcelona, Toutain Editor.

47 BEÀ, Josep María (2002): Historias de Taberna Galáctica, Barcelona, Glénat.

48 BeÀ, Josep María (2016): Historias de Taberna Galáctica. Edición definitiva, Barcelona,

${ }_{49}$ Madrid Brito, Débora (2017): «Extirpando los recuerdos. La Transición española como experimento de laboratorio en el cine de ciencia ficción de los 70», en Marcos Ramos, María (ed.), Historia, literatura y arte en el cine en español y portugués: estudios y perspectivas, s. l., Centro de Estudios Brasileños, pp. 72-86, espec. p. 74, http://www.cebusal.es/download/libro-cihalcep-web-ok.pdf (fecha de consulta: 27-VII-2019).

50 Ángel Moreno, Fernando: op. cit., p. 105. 
El otro día en una sesión de firmas, vino un hombre y me dijo que le había salvado la vida con la lectura de Historias de la Taberna Galáctica. Hacía más de treinta años que quería hablar conmigo, venía de Madrid. Cuando lo leyó, él estaba en un centro psiquiátrico y no tenía forma de ponerse bien, ni por fármacos ni por psicoterapia. El único alimento que le mantuvo en pie fue Historias de la Taberna Galáctica. Puede ser que este individuo me mintiera o puede que conectara con algo. Parece ser que Historias de la Taberna Galáctica transmite una emoción muy especial. En Rambla nos escribían mucho desde manicomios o cárceles. Algo que también le ocurría a El Vibora. Puede ser que ciertos personajes transfieran algo de lo que yo no soy consciente y que no sé si podría transmitir de nuevo ${ }^{51}$.

En palabras de José Manuel Trabado:

Es interesante comprobar el modo en que los autores utilizan aquellos géneros establecidos para ir inoculando en ellos una nueva sensibilidad. Se trata, pues, de una fina reinterpretación en la que el género supone un territorio fronterizo entre lo estandarizado del encargo y la visión genuina del autor en pos de su propia poética ${ }^{52}$.

Es decir: narración y grafismo nos hablan conjuntamente de la transmisión de algo «muy especial» que Beà logró aportar a la taberna. Transmiten una huella personal dentro de la ciencia ficción. Consiguen partir del género para sobrepasarlo, auspiciando una creciente conciencia autoral que se consolidará en las dos décadas siguientes. Todo ello convierte a Historias de Taberna Galáctica en una obra de referencia no sólo en el territorio de la ciencia ficción, sino en la historia del cómic español.

Recibido: marzo de 2020; ACEPTADO: mayo de 2020

${ }^{51}$ Entrevista a Josep María Beà en Barcelona, realizada el 24 de abril de 2017.

52 Trabado Cabado, J.M. (2019): «Del quiosco al museo o cómo nace la conciencia de autor", en Trabado Cabado, J.M. (ed.): Género y conciencia autoral en el cómic español (1970-2018), Servicio de Publicaciones de la Universidad de León y EOLAS Ediciones, pp. 9-38, espec., p. 14. 


\section{BIBLIOGRAFÍA}

Altarriba, Antonio (2001): La España del Tebeo. La Historieta Española de 1940 a 2000, Madrid, Espasa Calpe.

Anderson Imbert, Enrique (1992): Teoría y técnica del cuento, Barcelona, Editorial Ariel.

Ángel Moreno, Fernando (2007): «Notas para una historia de la ciencia ficción en España», Dicenda: Estudios de lengua y literatura españolas, 25, Madrid, Universidad Complutense, Servicio de Publicaciones, pp. 125-138.

Ángel Moreno, Fernando (2010): Teoría de la Literatura de Ciencia Ficción. Poética y Retórica de lo Prospectivo, Vitoria, Portal Editions.

Anónimo (1984): «Anecdotario», 1984, 64, Barcelona, Toutain Editor, pp. 4-5.

Barrero, Manuel (2003): "Cosiendo olas con tonsura descentrada. Entrevista a J.M. Beà», Sevilla, Tebeosfera, https://www.tebeosfera.com/1/Documento/Entrevista/Bea/JM.htm (fecha de consulta: 27-VII-2019).

BEÀ, Josep María (1980): «Relato de Blydhan», 1984, 20, Barcelona, Toutain Editor, pp. 57-64.

BEÀ, Josep María (1981): «Relato de Clakster», 1984, 28, Barcelona, Toutain Editor, pp. 69-72.

BEÀ, Josep María (1979), «Relato de Hycrotan», 1984, 13, Barcelona, Toutain Editor, pp. 49-56.

BEÀ, Josep María (1980): «Relato de Khantrax», 1984, 17, Barcelona, Toutain Editor, pp. 55-62.

BEÀ, Josep María (1980): «Relato de Kiramow», 1984, 23, Barcelona, Toutain Editor, pp. 65-72.

BEÀ, Josep María (1980): «Relato de Nacrapt», 1984, 25, Barcelona, Toutain Editor, pp. 64-71.

BEÀ, Josep María (1980): «Relato de Okaris», 1984, 19, Barcelona, Toutain Editor, pp. 57-64.

BEÀ, Josep María (1980): «Relato de Ondrakor», 1984, 16, Barcelona, Toutain Editor, pp. 6-9.

BEÀ, Josep María (1980): «Relato de Romagosa», 1984, 27, Barcelona, Toutain Editor, pp. 65-72.

BEÀ, Josep María (1980): «Relato de Syanock», 1984, 26, Barcelona, Toutain Editor, pp. 64-71.

BEÀ, Josep María (1980): «Relato de Tenyktar», 1984, 18, Barcelona, Toutain Editor, pp. 57-64.

BEÀ, Josep María (1979): «Relato de Toksath», 1984, 14, Barcelona, Toutain Editor, pp. 49-56.

BEÀ, Josep María (1979): «Unidad de servicio 3M», 1984, 11, Barcelona, Toutain Editor, pp. 50-57.

BEÀ, Josep María (1980): «Relato de Wanshott», 1984, 21, Barcelona, Toutain Editor, pp. 57-64.

BEÀ, Josep María (1980): «Relato de Zherbis», 1984, 22, Barcelona, Toutain Editor, pp. 53-60.

El editor (1978): «Presentación», 1984, 1, Barcelona, Toutain Editor, p. 2.

El tío Berni (10-VI-2008): «Entrevista a Josep María Beà», Entrecomics, http://www.entrecomics. com/?p=15963 (fecha de consulta: 27-VII-2019).

García Rouco, Diego y Cardona, Tristán (01-V-2019): «Entrevista a Josep M. aà,, Zona Negativa, https://www.zonanegativa.com/entrevista-a-josep-ma-bea/ (fecha de consulta: 27-VII-2019).

Infame\&Co (31-VIII-2017): «Mi vida siempre ha sido algo surrealista». Entrevista a Josep María Beà», El Portaluco, https://elportaluco.com/vida-siempre-ha-algo-surrealista-entrevista-josep-maria-bea/ (fecha de consulta: 27-VII-2019).

Lladó, Francisca (2001): Los Cómics de la Transición (El boom del cómic adulto 1975-1984), Barcelona, Glénat. 
Madrid Brito, Débora (2017): «Extirpando los recuerdos. La Transición española como experimento de laboratorio en el cine de ciencia ficción de los 70», en Marcos Ramos, María (ed.), Historia, literatura y arte en el cine en español y portugués: estudios y perspectivas, s.l., Centro de Estudios Brasileños, pp. 72-86, http://www.cebusal.es/download/libro-cihalcep-web-ok.pdf (fecha de consulta: 27-VII-2019).

Martín Cerezo, Iván (2006): «Poética del relato policiaco (de Edgar Allan Poe a Raymond Chandler)», Murcia, Universidad de Murcia, Servicio de Publicaciones.

Mora Bordel, Javier (2003): «En un lugar de la mente», Tebeosfera, Sevilla, https://www.tebeosfera.com/1/Obra/Tebeo/Glenat/EnunLugarde...2.htm (fecha de consulta: 27-VII-2019).

Mora Bordel, Javier y Barrero, Manuel (2009): «Beà. Psiconauta de la historieta», Sevilla, Tebeosfera, 3, 2009, https://www.tebeosfera.com/documentos/bea._psiconauta_de_la_historieta. html (fecha de consulta: 27-VII-2019).

Olmedo, Ivan (2003): «Historias de Taberna Galáctica», Tebeosfera, Sevilla, https://www.tebeosfera.com/1/Obra/Tebeo/Glenat/TabernaGalactica.htm (fecha de consulta: 27-VII-2019).

PÉREZ, Pepo (2018): «¿ «Solo para adultos»? Del boom al crack. La ficción de género en las revistas españolas de cómic de los ochenta", en Vilches, Gerardo (coord.): Del boom al crack. La explosión del cómic adulto en España (1977-1995), Madrid, Diminuta Editorial, 2018, pp. 57-92.

Pons, Álvaro (2011): «La industria del cómic en España: Radiografía de ¿̨un mito o una realidad?», ARBOR Ciencia, Pensamiento y Cultura, 187, extra 2, pp. 265-273, http://arbor.revistas. csic.es/index.php/arbor/article/view/1381/1390 (fecha de consulta: 27-VII-2019).

Toutain, Josep (1992): «Comix \& Comics», Zona 84, 96, p. 4.

Trabado Cabado, J.M. (2019): «Del quiosco al museo o cómo nace la conciencia de autor», en TraBado Cabado, J.M. (ed.), Género y conciencia autoral en el cómic español (1970-2018), Servicio de Publicaciones de la Universidad de León y EOLAS Ediciones, pp. 9-38. 
